\title{
How Should Functional Somatic Syndromes Be Diagnosed?
}

\author{
Samuel B. Harvey • Simon Wessely
}

Published online: 12 March 2013

(C) International Society of Behavioral Medicine 2013

Professor Nater and the editorial team at the International Journal of Behavioural Medicine should be congratulated on bringing together such a wide-ranging and interesting collection of papers for this special issue focused on functional somatic syndromes (FSS). While the papers contained within this issue appear, at first glance, to be diverse, we propose that there are three key themes running through this special issue. Firstly, the resolution of current debates surrounding the definition, identification and management of FSS is not merely of academic interest but has profound public health implications. Secondly, recent proposals to change the definition of somatoform disorders represent a useful step towards diminishing the dualistic approaches which have plagued the area of behavioural medicine, and finally, there is now sufficient evidence for FSS to begin to move away from being purely diagnoses of exclusion. The fact that these three topics emerged within this special edition is not by chance. Each of these topics maps onto some of the key current challenges in the field of consultation liaison psychiatry and behavioural medicine more generally.

Regardless of the exact definition used, there is a broad consensus that FSS are common [1-3]. The prevalence study by Fischer et al. published in this special issue demonstrates that FSS remain common even amongst a nonclinical sample of young students, with almost one in ten of the students fulfilling criteria for at least one FSS. However, the problem with FSS is not just that they are common but the fact that those who suffer from them experience significant distress and may have severe functional impairment. For example, a recent study of British patients with chronic

\footnotetext{
S. B. Harvey $(\bowtie)$

School of Psychiatry, University of New South Wales, Black Dog Institute, Hospital Road, Randwick,

Sydney, NSW 2031, Australia

e-mail: s.harvey@unsw.edu.au

S. B. Harvey - S. Wessely

Institute of Psychiatry, King's College London, London, UK
}

fatigue syndrome found that over $40 \%$ of those seeking treatment were on long-term sickness absence [4]. Similar observations have also been made when looking at other FSS, such as pain disorders [5].

Recently, there has been considerable debate surrounding how somatoform disorders should be defined and classified. Within DSM IV, somatisation disorder was defined by the presence of physical complaints across multiple body systems which were not feigned and could not be adequately explained by a general medical condition [6]. A number of authors have criticised this definition, noting that the idea that symptoms can be divided into those totally explained by physical conditions and those that are 'medically unexplained' is almost certainly false, not reflective of good clinical practice and encourages a dualistic divide between medicine and psychiatry [7]. We and others have previously discussed the dangers of such dualistic approaches with other disorders, such as chronic fatigue [8]. We now have strong evidence for the role of psychological factors as risk and maintaining factors in many cases of 'medically unexplained' fatigue [9-12]. However, we also know that there are biological systems, such as the HPA axis and immune function, which appear to be important in maintaining symptoms once they are established [13, 14]. Similarly, there are numerous studies demonstrating that fatigue, apparently due to clear physical illnesses, is often more closely associated with behavioural and psychological factors than with the severity of the underlying illness. For example, amongst HIV-infected patients, fatigue is more strongly associated with psychological factors than with measures of HIV disease progression or the use of highly active antiretroviral drugs [15]. There is also evidence that behaviourally focused interventions are one of the most effective ways of reducing fatigue, even when there is a clear underlying cause, such as rheumatoid arthritis, multiple sclerosis or cancer $[16,17]$.

In the context of growing discontent with a focus on whether symptoms were medically explainable, the recent proposals for DSM V suggest combining a range of 
somatoform disorders (somatisation disorder, undifferentiated somatoform disorder and hypochondriasis) into one central diagnosis to be called somatic symptom disorder [18]. The American Psychiatric Association is currently making near final revisions to the proposed criteria for DSM V, meaning they have removed the draft criteria from their website (http:// www.dsm5.org). However, it is clear from earlier drafts that the new diagnosis of somatic symptom disorder (which may be split into complex and simple somatic symptom disorder) will no longer require symptoms to be medically unexplained and that, instead, there will be a greater focus on the level of thoughts, feelings and behaviours related to these somatic symptoms or associated health concerns [18]. These proposed changes are not without critics, who fear that the new guidelines will result in many patients with normal emotional reactions to a physical illness being wrongly labelled as mentally ill [19]. While concerns about overdiagnosis are important, the fact that non-psychiatrists tend not to be aware of, and do not use, the DSM diagnostic criteria means any real-world impact on the way physical symptoms are managed will be limited.

While there is no suggestion of specific FSS such as chronic fatigue syndrome being included in the new DSM V, the move away from dualistic separation in somatoform disorders is relevant and will hopefully prompt similar discussions around how FSS should be considered and classified. The general move away from a focus solely on whether symptoms can be medically explained is supported by two of the papers within this special issue. Klaus et al. use population-level data to show that the level of functional impairment associated with symptoms and the degree of stability of complaints over time were the same, regardless of whether the symptoms were classified as medically explained or medically unexplained. The factor analysis of FSS presented by Witthöft et al., which suggested a two-factor model with one general somatisation factor and a range of symptomspecific factors, also provides support for a common tendency towards somatisation amongst a range of disorders.

The final issue addressed by the papers presenting in the issue is how a diagnosis of FSS is made. Articles by Kingma et al. and Marques et al. highlight the fact that there are a range of individual and societal factors which may influence whether a symptomatic individual receives a diagnosis of FSS. In addition, it remains the case that FSS are usually a diagnosis of exclusion, which are only contemplated and discussed once a search for a physical cause has been exhausted. While the exclusion of medical causes of symptoms is important, there are a range of factors that should heighten a clinician's awareness of the possibility of FSS. These can be pre-morbid factors known to be risk factors of FSS, such as being female [2], having prior psychiatric disorders $[9,20,21]$, prior experience of illness in the family and previous unexplained symptoms in the individual [22, 23], levels of social adjustment [24] or, as highlighted by
Kempke et al.'s article in this issue, certain personality styles [25], although it is fair to say that evidence on the role of personality and personality disorder is conflicting [24]. Additionally, factors around the way in which an individual describes their symptoms or examination findings may be positive signs of a functional disorder [26]. A proactive approach to diagnosing FSS obviously needs to be balanced against due care to avoid missing other diagnoses. However, when the possibility of FSS is only considered as a last resort after a long period of fruitless investigation, patients are often left confused, without access to effective treatments and with a sense that a diagnosis of FSS means their doctors have 'given up on them', something that is merely confirmed when the patient is referred to a mental health professional [27].

While it is important for FSS to be diagnosed in an early, proactive way, clinicians need to be aware that making a diagnosis of any FSS is not in itself a neutral act. For example, those who have symptoms suggestive of chronic fatigue syndrome who acquire certain labels such as 'myalgic encephalomyelitis' appear to do worse [28, 29]. One can speculate that much the same might happen to soldiers who receive a label of 'mild traumatic brain injury' as opposed to 'concussion'. Labels themselves convey meanings. Clinicians must remember that giving a label is not the end of the consultation, but the beginning. If handled well, the patient can receive an endorsement of the legitimacy and validation of their symptoms and illness, and then start to engage in a constructive dialogue on ways forward. Handled poorly and the result can be an entrenchment of views, a reinforcement of what may be an inaccurate and unhelpful illness model, and an antagonistic relationship that benefits neither patient nor the health professional [30, 31].

The papers presented in this special edition once again remind us that FSS are common, disabling disorders which can be a challenge to diagnose and manage. However, the field of behavioural medicine should take some pride in the fact that there are now effective treatments available for these debilitating conditions [32-34]. The current discussions around classifications and how to diagnose FSS are complex but important and have the potential to reduce the stigma, dualistic views and treatment delays. We once again thank the editorial team and the journal for bringing together this thought-provoking collection of studies.

\section{References}

1. Wessely S, Chalder T, Hirsch S, Wallace P, Wright D. The prevalence and morbidity of chronic fatigue and chronic fatigue syndrome: a prospective primary care study. Am J Publ Health. 1997;87(9):1449-55. 
2. Lovell RM, Ford AC. Global prevalence of and risk factors for irritable bowel syndrome: a meta-analysis. Clinical gastroenterology and hepatology. Off Clin Pract J Am Gastroenterol Assoc. 2012;10(7):712-21. doi:10.1016/j.cgh.2012.02.029. e4.

3. Wolfe F, Ross K, Anderson J, Russell IJ, Hebert L. The prevalence and characteristics of fibromyalgia in the general population. Arthritis Rheum. 1995;38(1):19-28.

4. Knudsen AK, Henderson M, Harvey SB, Chalder T. Longterm sickness absence among patients with chronic fatigue syndrome. Br J Psychiatry. 2011;199(5):430-1. doi:10.1192/ bjp.bp.110.082974.

5. Overland S, Harvey SB, Knudsen AK, Mykletun A, Hotopf M. Widespread pain and medically certified disability pension in the Hordaland Health Study. Eur J Pain. 2011. doi:10.1016/ j.ejpain.2011.08.005.

6. APA. Diagnostic and statistical manual of mental disorders. 4th ed. Washington DC: American Psychiatric Association; 1994.

7. Mayou R, Kirmayer LJ, Simon G, Kroenke K, Sharpe M. Somatoform disorders: time for a new approach in DSM-V. Am J Psychiatry. 2005;162(5):847-55. doi:10.1176/appi.ajp.162.5.847.

8. Harvey SB, Wessely S. Chronic fatigue syndrome: identifying zebras amongst the horses. BMC Med. 2009;7:58. doi:10.1186/ 1741-7015-7-58.

9. Harvey SB, Wadsworth M, Wessely S, Hotopf M. The relationship between prior psychiatric disorder and chronic fatigue: evidence from a national birth cohort study. Psychol Med. 2008;38(7):933-40.

10. Harvey SB, Wadsworth M, Wessely S, Hotopf M. Etiology of chronic fatigue syndrome: testing popular hypotheses using a national birth cohort study. Psychosom Med. 2008;70(4):488-95.

11. White PD. What causes chronic fatigue syndrome? BMJ. 2004;329(7472):928-9. doi:10.1136/bmj.329.7472.928.

12. Clark C, Goodwin L, Stansfeld SA, Hotopf M, White PD. Premorbid risk markers for chronic fatigue syndrome in the 1958 British birth cohort. Br J Psychiatry. 2011;199(4):323-9. doi:10.1192/bjp.bp.110.083956.

13. Cleare AJ. The HPA, axis and the genesis of chronic fatigue syndrome. Trends Endocrinol Metab. 2004;15(2):55-9. doi:10.1016/j.tem.2003.12.002.

14. Lyall M, Peakman M, Wessely S. A systematic review and critical evaluation of the immunology of chronic fatigue syndrome. J Psychosom Res. 2003;55(2):79-90.

15. Henderson M, Safa F, Easterbrook P, Hotopf M. Fatigue among HIV-infected patients in the era of highly active antiretroviral therapy. HIV Med. 2005;6(5):347-52.

16. Armes J, Chalder T, Addington-Hall J, Richardson A, Hotopf M. A randomized controlled trial to evaluate the effectiveness of a brief, behaviorally oriented intervention for cancer-related fatigue. Cancer. 2007;110(6):1385-95. doi:10.1002/cncr.22923.

17. Neill J, Belan I, Ried K. Effectiveness of non-pharmacological interventions for fatigue in adults with multiple sclerosis, rheumatoid arthritis, or systemic lupus erythematosus: a systematic review. J Adv Nurs. 2006;56(6):617-35. doi:10.1111/j.13652648.2006.04054.x.

18. APA. Somatic symptom disorders. 2011. http://www. dsm5.org/Documents/Somatic/Somatic\%20Symptom
\%20Disorders\%20description\%20April\%2018,\%202011.pdf. Accessed 16 Dec 2012.

19. Frances A. Mislabeling medical illness as mental disorder. In: DSM5 in distress. Psychology Today. 2012. http:// www.psychologytoday.com/blog/dsm5-in-distress/201212/ mislabeling-medical-illness-mental-disorder. Accessed 16 Dec 2012.

20. Harvey SB, Wessely S, Kuh D, Hotopf M. The relationship between fatigue and psychiatric disorders: evidence for the concept of neurasthenia. J Psychosom Res. 2009;66(5):445-54. doi:10.1016/j.jpsychores.2008.12.007.

21. Goodwin L, White PD, Hotopf M, Stansfeld SA, Clark C. Psychopathology and physical activity as predictors of chronic fatigue syndrome in the 1958 British birth cohort: a replication study of the 1946 and 1970 birth cohorts. Ann Epidemiol. 2011;21(5):343-50. doi:10.1016/j.annepidem.2010.12.003.

22. Hotopf M, Mayou R, Wadsworth M, Wessely S. Childhood risk factors for adults with medically unexplained symptoms: results from a national birth cohort study. Am J Psychiatry. 1999;156(11):1796-800.

23. Hotopf M, Wilson-Jones C, Mayou R, Wadsworth M, Wessely S. Childhood predictors of adult medically unexplained hospitalisations. Results from a national birth cohort study. Br J Psychiatry. 2000;176:273-80.

24. Wood B, Wessely S. Personality and social attitudes in chronic fatigue syndrome. J Psychosom Res. 1999;47(4):385-97.

25. Kato K, Sullivan PF, Evengard B, Pedersen NL. Premorbid predictors of chronic fatigue. Arch Gen Psychiatry. 2006;63(11):1267-72. doi:10.1001/archpsyc.63.11.1267.

26. Stone J, Carson A, Sharpe M. Functional symptoms and signs in neurology: assessment and diagnosis. J Neurol Neurosurg Psychiatry. 2005;76 Suppl 1:i2-12. doi:10.1136/jnnp.2004.061655.

27. Deale A, Wessely S. Patients' perceptions of medical care in chronic fatigue syndrome. Soc Sci Med. 2001;52(12):1859-64.

28. Chalder T, Power MJ, Wessely S. Chronic fatigue in the community: 'a question of attribution'. Psychol Med. 1996;26(4):791-800.

29. Hamilton WT, Gallagher AM, Thomas JM, White PD. The prognosis of different fatigue diagnostic labels: a longitudinal survey. Fam Pract. 2005;22(4):383-8. doi:10.1093/fampra/cmi021.

30. Kouyanou K, Pither CE, Wessely S. Iatrogenic factors and chronic pain. Psychosom Med. 1997;59(6):597-604.

31. Page LA, Wessely S. Medically unexplained symptoms: exacerbating factors in the doctor-patient encounter. J R Soc Med. 2003;96(5): $223-7$.

32. Harvey SB, Wessely S. Tired all the time: can new research on fatigue help clinicians? Br J Gen Pract. 2009;59(561):237-9. doi:10.3399/bjgp09X420284.

33. White PD, Goldsmith KA, Johnson AL, et al. Comparison of adaptive pacing therapy, cognitive behaviour therapy, graded exercise therapy, and specialist medical care for chronic fatigue syndrome (PACE): a randomised trial. Lancet. 2011;377(9768):823-36. doi:10.1016/S01406736(11)60096-2.

34. Kennedy T, Jones R, Darnley S, Seed P, Wessely S, Chalder T. Cognitive behaviour therapy in addition to antispasmodic treatment for irritable bowel syndrome in primary care: randomised controlled trial. BMJ. 2005;331(7514):435. 